\title{
Prognostic factors for metastasis in cutaneous melanoma*
}

\author{
Ana Carolina Figueiredo Pereira Cherobin ${ }^{1}$ \\ Enrico Antônio Colosimo ${ }^{3}$ \\ Flávia Vasques Bittencourt ${ }^{1}$
}

\author{
Alberto Julius Alves Wainstein ${ }^{2}$ \\ Eugênio Marcos Andrade Goulart ${ }^{4}$
}

DOI: http:/ / dx.doi.org/10.1590/abd1806-4841.20184779

\begin{abstract}
BACKGROUND: Melanoma is a malignant neoplasia that shows high mortality when diagnosed in advanced stages. Early identification of high-risk patients for the development of melanoma metastases is the main strategy to reduce mortality.

Овјестіvе: To assess the influence of eight epidemiological and histopathologic features on the development of metastases in patients diagnosed with primary cutaneous melanoma.

METHODS: Our historical cohort comprised patients with invasive primary cutaneous melanoma seen between 1995 and 2012 at a public university hospital and a private oncologic surgery institution in Southeastern Brazil. The following variables were analyzed: gender, age, family history of melanoma, site of the primary tumor, clinical and histologic subtype, Breslow thickness, histologic ulceration and the mitotic index. Kaplan-Meier univariate test and multivariate Cox proportional hazard analysis were used to assess factors associated with disease-free survival.

RESULTS: Five hundred and fourteen patients were enrolled. The univariate analysis identified the following significant risk factors: gender, age, site of the tumor, clinical and histologic subtype, Breslow thickness, histologic ulceration and mitotic index. Multivariate analysis included 244 patients and detected four significant prognostic factors: male gender, nodular clinical and histologic subtype, Breslow thickness $>4 \mathrm{~mm}$, and histologic ulceration. The mitotic index was not included in this analysis.

STUDY LIMITATIONS: Small number of patients in multivariate analysis.

CONCLUSIONS: The following prognostic factors to the development of melanoma metastasis were identified in the study: male gender, nodular histologic subtype, Breslow thickness $>4 \mathrm{~mm}$ and ulceration.
\end{abstract}

Keywords: Melanoma; Neoplastic metastasis; Skin cancers

\section{INTRODUCTION}

Melanoma is an aggressive tumor with high mortality when diagnosed in advanced stages. Its incidence is increasing drastically all over the world, as well as its cases of death. ${ }^{1,2}$ Despite promising therapeutic advances, treatments capable of significantly prolonging the survival of patients with metastasis have not yet been developed. For this reason, the main strategy to reduce mortality is based on the early identification of the primary tumor and of the patients at risk for metastatic disease. ${ }^{3}$

Different risk factors for the development of cutaneous melanoma metastases were studied extensively. Clinical and epidemiological aspects such as age, gender and site of the tumor are associated to disease progression. ${ }^{4}$ Certain histopathologic, immunologic, genetic and molecular characteristics were also implicated in the development of melanoma metastasis. ${ }^{1,5}$

Received on 03.06.2015.

Approved by the Advisory Board and accepted for publication on 04.08.2016.

Study conducted at Hospital das Clínicas, Universidade Federal de Minas Gerais (UFMG) - Belo Horizonte (MG), Brazil and Surgical Oncology and Digestive System Surgery (ONCAD) - Belo Horizonte (MG), Brazil

Financial support: None.

Conflict of interest: None

Department of Dermatology, Hospital das Clínicas, Universidade Federal de Minas Gerais (HC-UFMG) - Belo Horizonte (MG), Brazil. Institute of Post-graduation, Faculdade de Ciências Médicas de Minas Gerais (FCM-MG) - Belo Horizonte (MG), Brazil.

Department of Statistics, Institute of Exact Sciences, Universidade Federal de Minas Gerais (ICEx-UFMG) - Belo Horizonte (MG), Brazil.

Department of Pediatrics, Faculdade de Medicina da Universidade Federal de Minas Gerais (UFMG) - Belo Horizonte (MG), Brazil.

\section{MAILING ADDRESS:}

Ana Carolina Figueiredo Pereira Cherobin

E-mail: anacherobin@yahoo.com.br

(C2018 by Anais Brasileiros de Dermatologia

Due to the alarming increase in the incidence of melanoma and to the high mortality rates from metastatic disease, the data of patients seen with primary melanoma in the department of dermatology of a university hospital and a private surgical oncology practice between 1995 and 2012 were analyzed with the aim of identifying prognostic factors for the development of metastasis in melanoma.

\section{METHODS}

Study Population

This is a historical cohort, with data collection from patients' files. Between January 1995 and January 2012, 212 patients with suspicion of melanoma were admitted to the department of dermatology of the Hospital das Clínicas, Universidade Federal 
de Minas Gerais (HC-UFMG) and 568 patients to the private surgical oncology practice ONCAD (Oncologia Cirúrgica e Cirurgia do Aparelho Digestivo), both in the Southeastern region of Brazil. Of the total of 780 patients, 266 individuals were initially excluded: 137 with melanoma in situ, 12 younger than 18 years of age, 19 for having a non-cutaneous primary melanoma, 6 with the diagnosis of genodermatoses, 19 with unknown primary tumor, 26 with a follow-up shorter than 1 month, 12 with indeterminate follow-up, 4 with melanoma associated to giant congenital melanocytic nevus, 20 with multiple melanomas and 11 patients being followed in both services (table 1). Therefore, 514 patients were included in the study.

The patients selected for the statistical analysis fulfilled the following inclusion criteria: diagnosis of invasive primary cutaneous melanoma confirmed by histopathology, age equal to or above 18 years and a minimum follow-up time of 1 month.

Patient follow-up in each service was conducted according to well-established protocols in the literature. Clinical evaluation was trimonthly in the first year after the diagnosis, four to six-monthly in the second year and annually thereafter. Follow-up interval was reduced according to the presence of risk factors for tumor spread. Follow-up included physical examination, chest X-ray and levels of serum lactic dehydrogenase, with the goal of detecting recurrences and local or distant metastases. In the cases with risk for spread, other imaging studies were requested, according to the affected area. Patients classified as stage IB or II were referred for sentinel lymph node biopsy.

The project was approved by the Committee of Research Ethics of the institution.

The patients that were still being seen at the services during the time of data collection signed a consent form.

\section{Anatomopathological examination}

The diagnosis of cutaneous melanoma was performed by anatomopathological examination. At the service of dermatology,

TABLE 1: Patients included in and excluded from the final statistical analysis (1995-2012)

\begin{tabular}{|c|c|c|}
\hline Variable & $\begin{array}{c}\text { Service of } \\
\text { Dermatology }\end{array}$ & $\begin{array}{c}\text { Service of } \\
\text { Surgical } \\
\text { Oncology }\end{array}$ \\
\hline Total of admitted patients & 212 & 568 \\
\hline \multicolumn{3}{|l|}{ Exclusion criteria } \\
\hline In situ cutaneous melanoma & 60 & 77 \\
\hline Age $<18$ years & 01 & 11 \\
\hline Non-cutaneous primary melanoma & 00 & 19 \\
\hline Genodermatoses & 03 & 03 \\
\hline Unknown primary site & 04 & 15 \\
\hline Insufficient follow-up & 01 & 25 \\
\hline Unknown follow-up & 06 & 06 \\
\hline Melanoma associated to GCMN & 03 & 01 \\
\hline Multiple melanomas & 19 & 01 \\
\hline Common patients & 01 & 10 \\
\hline Total of excluded patients & 98 & 168 \\
\hline Total of included patients & 114 & 400 \\
\hline
\end{tabular}

GCMN: Giant congenital melanocytic nevus only one experienced dermatopathologist was responsible for the analysis of the cases. At the service of surgical oncology, the diagnosis was obtained by the validation or review of the reports by a pathologist with a wide experience in melanocytic lesions.

\section{Follow-up}

The time for the follow-up of patients was defined as the interval between the date of diagnosis of the primary cutaneous melanoma (time zero) and the date of the last consultation or the date of the diagnosis of melanoma metastasis, in the cases where the disease spread (date of outcome). Data from patients' files with a minimum follow-up of one month were included.

\section{Statistical analysis}

Disease free survival was calculated considering the period between the diagnosis of primary cutaneous melanoma and the diagnosis of metastasis or the date of the last consultation. Survival analysis was calculated by univariate analysis, with the Kaplan-Meier curves, log-rank test and the multivariate Cox proportional hazard analysis to obtain the risk factors for the occurrence of metastasis of the 514 patients included in the study. The variables with $p<0.25$ in the multivariate analysis were submitted to analysis by the Cox model. The value of $\mathrm{p}<0.05$ was considered statistically significant. Student $\mathrm{t}$ test was utilized to compare age means and Mann-Whitney test for the follow-up period. Schoenfeld residuals test was applied to the analyses to evaluate model adequacy and considered $p>0.05$ as adequate. Statistical analyses were performed using software R.

\section{RESULTS}

Analysis of the characteristics of primary cutaneous melanoma

According to clinical and epidemiological characteristics, most were females (57.4\%), Caucasian (67.9\%), older than 40 years (74.1\%) and had no family history of melanoma (69.3\%). Regarding the site, most tumors were located on the limbs (53.5\%). Regarding the histologic features, there was a predominance of the superficial spreading histologic type (39.3\%) and thin tumors ( $\leq 1 \mathrm{~mm})(45.9 \%)$. The distribution of the tumors between the different levels of Clark was similar (28.6 to $29 \%$ ). Of the total of 514 patients, $271(52.7 \%)$ had information of ulceration on the anatomopathological examination, with a predominance of non-ulcerated melanomas (39.1\%). Among the 292 (56.8\%) that had information of the presence of mitoses, most (39.9\%) had at least 1 mitosis $/ \mathrm{mm}^{2}$ (table 2).

There was loss of data regarding the following variables: skin color $(22 \%)$, age $(2 \%)$, family history of melanoma $(19.2 \%)$, site of the primary tumor (1.8\%), clinicopathological subtype $(27.6 \%)$, Clark level (13.4\%), Breslow thickness (15.2\%), ulceration $(47.3 \%)$ and mitotic index (43.2\%) (table 2).

Analysis of the characteristics of the patients with metastasis Of the total of 514 patients, $135(26.3 \%)$ had the diagnosis of metastasis during follow-up: $14(2.7 \%)$ seen at the department of dermatology and 121 (23.6\%) seen at the service of surgical oncology. Two hundred and ninety-two metastases of the 135 patients were diagnosed in different sites and, in 7 of those, the site was not specified. Regional metastases corresponded to $36.3 \%$ of the cases, local corresponded to $19.5 \%$ and distant metastases were responsi- 
TABLE 2: Clinical, epidemiologic and histopathologic features of the patients seen at the services of dermatology and surgical oncology (1995-2012)

\begin{tabular}{|c|c|c|}
\hline Variable & Number & $\%$ \\
\hline \multicolumn{3}{|l|}{ Gender } \\
\hline Male & 219 & 42.6 \\
\hline Female & 295 & 57.4 \\
\hline \multicolumn{3}{|l|}{ Skin type } \\
\hline Caucasian & 349 & 67.9 \\
\hline Brown & 48 & 9.3 \\
\hline Black & 4 & 0.8 \\
\hline Yellow* & 0 & 0 \\
\hline No information* & 113 & 22.0 \\
\hline \multicolumn{3}{|l|}{ Age } \\
\hline $18-40$ years & 123 & 23.9 \\
\hline 40-60 years & 195 & 37.9 \\
\hline$>60$ years & 186 & 36.2 \\
\hline No information* & 10 & 2.0 \\
\hline \multicolumn{3}{|l|}{ Family history of melanoma* } \\
\hline Yes & 59 & 11.5 \\
\hline No & 356 & 69.3 \\
\hline No information * & 99 & 19.2 \\
\hline \multicolumn{3}{|l|}{ Site } \\
\hline Head and neck & 88 & 17.1 \\
\hline Trunk & 187 & 36.4 \\
\hline Upper limbs & 65 & 12.6 \\
\hline Lower limbs & 80 & 15.6 \\
\hline Acral & 85 & 16.5 \\
\hline No information* & 9 & 1.8 \\
\hline \multicolumn{3}{|l|}{ Clinicopathological type } \\
\hline Superficial spreading & 202 & 39.3 \\
\hline Lentigo maligna melanoma & 38 & 7.4 \\
\hline Nodular & 74 & 14.4 \\
\hline Acral & 44 & 8.6 \\
\hline Other & 14 & 2.7 \\
\hline No information* & 142 & 27.6 \\
\hline \multicolumn{3}{|l|}{ Clark level } \\
\hline I and II & 147 & 28.6 \\
\hline III & 149 & 29.0 \\
\hline IV and V & 149 & 29.0 \\
\hline No information* & 69 & 13.4 \\
\hline \multicolumn{3}{|l|}{ Breslow thickness } \\
\hline$\leq 1 \mathrm{~mm}$ & 236 & 45.9 \\
\hline 1,01 to $2 \mathrm{~mm}$ & 86 & 16.7 \\
\hline 2,01 to $4 \mathrm{~mm}$ & 70 & 13.6 \\
\hline$>4 \mathrm{~mm}$ & 44 & 8.6 \\
\hline No information* & 78 & 15.2 \\
\hline \multicolumn{3}{|l|}{ Ulceration } \\
\hline Yes & 70 & 13.6 \\
\hline No & 201 & 39.1 \\
\hline No information* & 243 & 47.3 \\
\hline \multicolumn{3}{|l|}{ Mitotic index } \\
\hline 0 & 87 & 16.9 \\
\hline 1 to 4 & 137 & 26.7 \\
\hline 5 to 10 & 45 & 8.7 \\
\hline$\geq 11$ & 23 & 4.5 \\
\hline No information * & 222 & 43.2 \\
\hline
\end{tabular}

* Excluded from statistical analysis. ble for $44.2 \%$ of the total number of cases.

Among patients with melanoma metastasis, the mean age was 53 years ( \pm 17 years) and the median was 51 years. For those without metastasis, the mean age was 54 years ( \pm 17 years) and the median 53 years. There was no statistically significant difference between the groups $(p=0.697)$. The median duration of the cohort's follow-up was 24.7 months (ranging from 1 to 374 ). The median duration of follow-up for patients with metastasis was 12.2 months, significantly lower than those censored, which was 30.4 months $(\mathrm{p}<0.001)$.

Of the 514 patients, 447 (87\%) were diagnosed with the disease in the previous 10 years (Figure 1).

\section{Analysis of disease-free survival}

According to the univariate analysis by the Kaplan-Meier method and the log-rank test, the following variables were considered of risk for the occurrence of metastasis: male gender $(p=0.0007)$, nodular and acral clinicopathological types $(p<0.0001)$, Breslow thickness $>1 \mathrm{~mm}(\mathrm{p}<0.0001)$, ulceration $(\mathrm{p}<0.0001)$ (Figures 2 to 5$)$, age $>60$ years ( $p=0.0566$ ), acral location of the primary tumor $(p=0.0054)$ and mitotic index $(p<0.0001)$. Family history was not a significant variable $(\mathrm{p}=0.985)$.

\section{Multivariate analysis}

The multivariate analysis was conducted using the Cox model. It was not possible to include the mitotic index, for there were no patients with metastasis that did not have mitosis on the anatomopathological examination. The same occurred with the clinicopathological type lentigo maligna melanoma. For this reason, we opted to group it with the superficial spreading type, that presented the lowest melanoma metastasis risk when compared to the nodular and acral types. The variable of family history of the disease was not included because it did not reach statistical significance with the univariate analysis.

Thus, the following variables were included: gender, age, site of the primary tumor, clinicopathological type, Breslow thickness and ulceration. Therefore, 244 patients with complete information regarding all six variables above mentioned were analyzed.

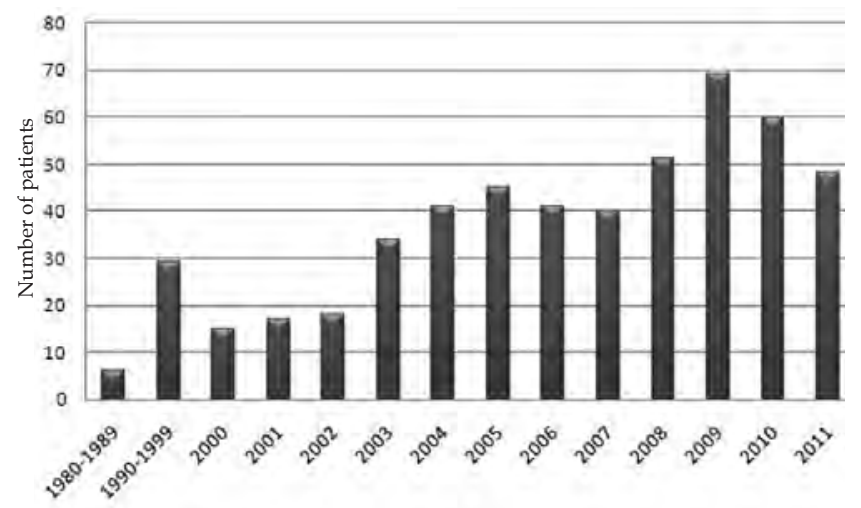

FIGURE 1: Number of patients diagnosed with cutaneous melanoma with time, seen at the services of dermatology and surgical oncology (1995-2012) 
Male gender $(p=0.0222)$, nodular clinicopathological type $(\mathrm{p}=0.0196)$, Breslow thickness $>4 \mathrm{~mm}(\mathrm{p}=0.0011)$ and ulceration $(p=0.0391)$ were considered risk factors for the occurrence of metastasis of primary cutaneous melanoma. Tumor thickness between 1 and $4 \mathrm{~mm}$ was close to statistical significance $(\mathrm{p}=0.0628)$. The acral clinicopathological type did not reach statistical significance $(p=0.4857)$ (table 3). The model's residuals test showed $p=0.611$.

\section{DISCUSSION}

Melanoma is an aggressive skin cancer, characterized by the high risk of metastasis and death. ${ }^{1}$ Although it represents only $4 \%$

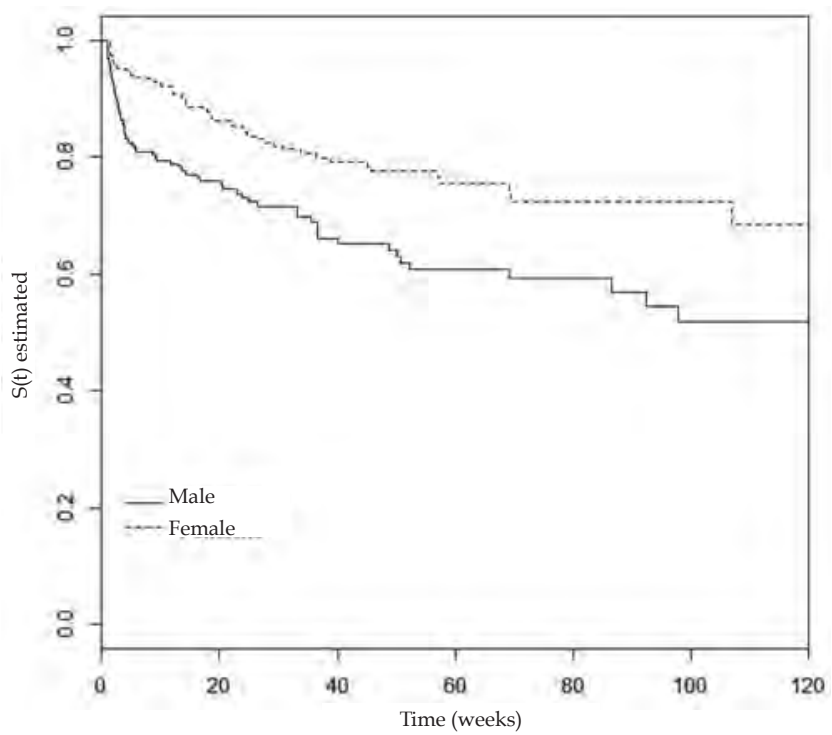

FIGURE 2: Kaplan-Meier curves showing the interval for the occurrence of metastasis in patients with primary cutaneous melanoma according to gender (1995-2012)

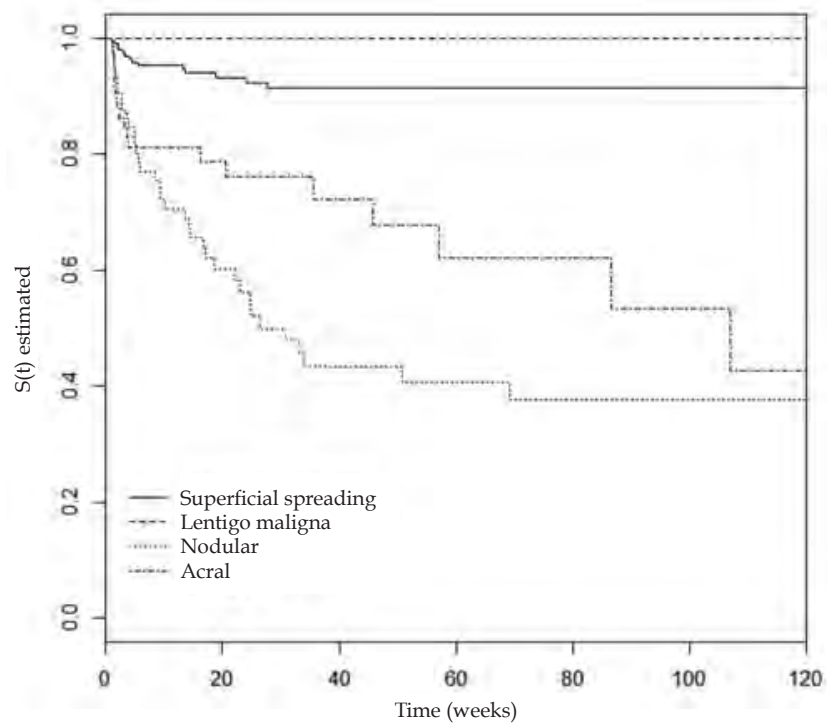

FIGURE 3: Kaplan-Meier curves illustrating the time for the occurrence of the metastasis in patients with primary cutaneous melanoma according to the clinicopathological type (1995-2012) of skin cancers in Brazil, it is responsible for the death of almost $50 \%$ of these patients. ${ }^{2}$

Data from 780 patients with the diagnosis of melanoma confirmed by anatomopathological examination seen at 2 reference centers participating in the study between 1995 and 2021 were collected. It is a large sample of cases included in a single Brazilian study.

In the sample studied, male gender, nodular clinicopathological type, Breslow thickness $>1 \mathrm{~mm}$ and the presence of ulceration were considered prognostic factors for the occurrence of metastasis.

Other authors also found a poorer course of melanoma in men. ${ }^{6,7}$ According to Pollack et al. ${ }^{4}$ men had a lower survival at 1

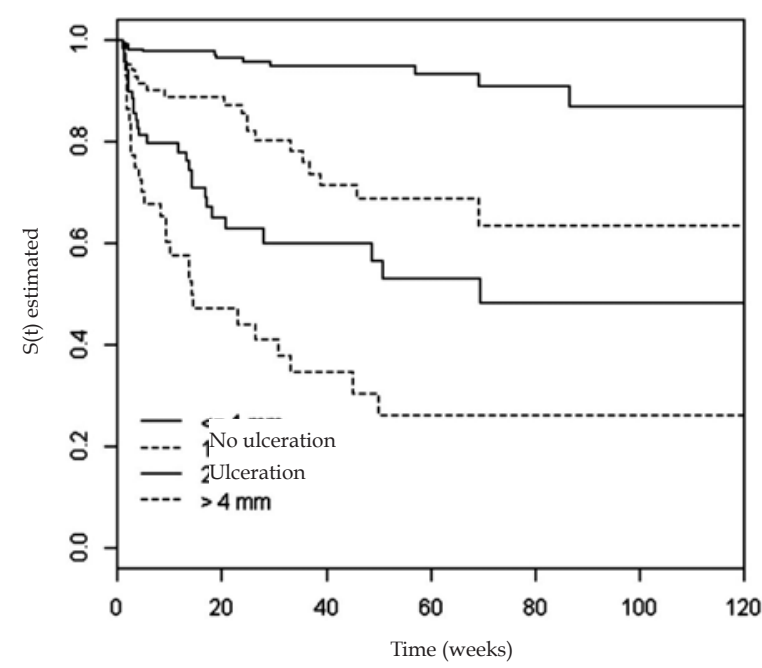

FIGURE 4: Kaplan-Meier curves illustrating the time for the occurrence of metastasis in patients with primary cutaneous melanoma according to Breslow thickness (1995-2012)

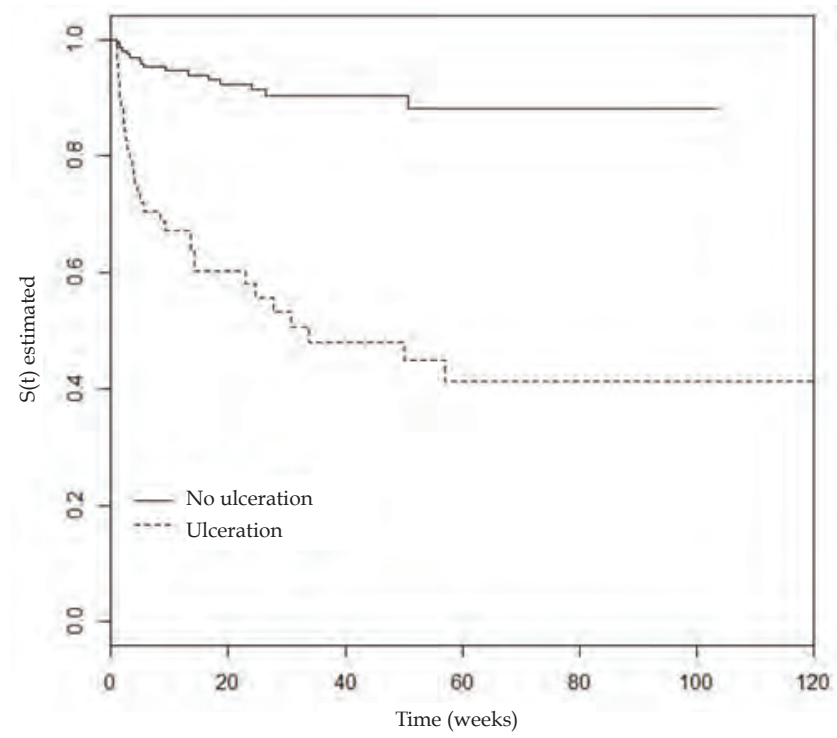

Figure 5: Kaplan-Meier curves illustrating the time for the occurrence of metastasis in patients with primary cutaneous melanoma according to the presence of ulceration (1995-2012) 
and 5 years, regardless of the age at melanoma diagnosis. Vries et al. ${ }^{8}$ showed that men have a 1.87 -fold higher risk of death by melanoma than women, even after adjusting for other risk features such as age, site of the primary tumor, clinicopathological type and Breslow thickness. Recently, Liljana Mervic, ${ }^{9}$ who followed 7,338 patients in a German university, showed that women had lower risks of melanoma spread and a longer interval between the primary tumor and the first metastasis. Besides, that study showed that females develop metastasis with a more favorable prognosis, such as satellite or in-transit metastasis, when compared to those of males.

The reason for the lower risk of melanoma spread in women is still unknown. A possible explanation for this could be the fact that women pay more attention to their own bodies and seek medical care earlier. ${ }^{10}$ Hormonal influence was also postulated as responsible for a longer survival in women, but recent studies suggest that melanoma is not hormone-dependent. ${ }^{11,12}$ In a recent study, Joosse et al.reported that oxygen free radicals, such as the superoxide anion and hydrogen peroxide, are involved in the mealanogenesis of the tumor. ${ }^{13}$ The authors postulated that the oxidative stress, more pronounced in men, could be responsible for the increased ability of melanoma to spread.

Patients with nodular melanoma had a 2.89-fold higher risk for disease spread when compared to the superficial spreading and lentigo maligna melanoma types, parameters used as reference and analyzed as group, independently from the other variables analyzed. The second highest risk type was acral melanoma. However, in the multivariate analysis, it did not reach statistical significance (HR: 1.50).

In 2010, Kunte et al. ${ }^{14}$ studied the risk factors for lymph node metastasis in patients with melanoma. The nodular clinicopathological type was the second most important prognostic factor for lymph node involvement, overcome only by tumor thickness. The same study showed that the nodular component in any other

TABLE 3: Cox multivariate analysis of the risk factors for primary cutaneous melanoma metastasis of 244 patients seen at the services of dermatology and surgical oncology (1995-2012)

\begin{tabular}{|c|c|c|c|}
\hline Variable & $\begin{array}{l}\text { Hazard } \\
\text { Ratio* }\end{array}$ & CI 95\% & P value \\
\hline \multicolumn{4}{|l|}{ Gender } \\
\hline Male & Reference** $^{* *}$ & & \\
\hline Female & 0.46 & $0.24-0.90$ & 0.0222 \\
\hline \multicolumn{4}{|l|}{ Clinicopathological type } \\
\hline $\begin{array}{l}\text { Superficial spreading } \\
\text { and lentigo maligna } \\
\text { melanoma }\end{array}$ & Reference & & \\
\hline Nodular & 2.89 & $1.19-7.03$ & 0.0196 \\
\hline Acral & 1.50 & $0.48-4.72$ & 0.4857 \\
\hline \multicolumn{4}{|l|}{ Breslow thickness } \\
\hline$\leq 1 \mathrm{~mm}$ & Reference & & \\
\hline 1,01 to $4 \mathrm{~mm}$ & 3.00 & $0.94-9.57$ & 0.0628 \\
\hline$>4 \mathrm{~mm}$ & 7.85 & $2.27-27.16$ & 0.0011 \\
\hline \multicolumn{4}{|l|}{ Ulceration } \\
\hline No & Reference & & \\
\hline Yes & 2.14 & $1.04-4.40$ & 0.0391 \\
\hline
\end{tabular}

CI: Confidence interval; *Risk of metastasis as calculated by the Cox method. **exp(-coef): 2.1509 clinicopathological type increased the likelihood of lymph node involvement. Superficial spreading melanomas without nodular component had an OR of 0.56 , and those with a nodular component had an OR of 0.78 . In this study, acral melanoma was also the second clinicopathological type of worse prognosis. Lindholm et al. ${ }^{7}$ prospective cohort also pointed towards a lower survival for patients with nodular melanoma. It is thought that the nodular type presents a worse prognosis due to its vertical growth, leading to a premature arrival of tumor cells in the lymphatic and blood vessels of the dermis. ${ }^{15-17}$ Distinct genetic characteristics can also explain the more aggressive course of this tumor. In 2008, Viros et al.demonstrated a high frequency of BRAF mutations (68.8\%) and a low frequency of NRAS mutations $(12.5 \%)$ in 16 patients with nodular melanoma. ${ }^{18}$ However, the influence of genetic abnormalities in the prognosis of melanoma is not yet established.

The acral type is also considered an independent risk factor for the occurrence of metastases. According to Garbe et al.,nodular and acral melanomas show a reduction in survival of 10 years, although its influence was smaller than other parameters as thickness, gender and site. ${ }^{19}$ The study that included the population of the program SEER (Surveillance, Epidemiology and End Results), with 51,704 patients of 13 different American institutions, indicated that acral melanoma was the one with lower 5-year and 10-year survival, from 1986 to $2005 .{ }^{9}$ The study by Chang et al. ${ }^{16}$ which included 181 Chinese patients, phototype III and IV (according to Fitzpatrick's classification), showed that acral and nodular melanoma were risk variables for the reduction of 5-year survival. Nonetheless, the authors affirmed that the importance of the clinicopathological type was inferior to the other variables such as gender, stage of the disease and tumor thickness, due to the reduction in the values of the HR from the univariate to the multivariate analysis.

Of all variables analyzed in this study, Breslow thickness was considered the most important for the occurrence of melanoma metastasis. As the thickness of the tumor increased, so did the risk of metastasis $(p=0.0628$ for tumors between $1-4 \mathrm{~mm}$ and $\mathrm{p}=0.0011$ for tumors $>4 \mathrm{~mm}$ ). Such result confirms the findings of various authors since the description of this variable by Breslow in $1970 .{ }^{20} \mathrm{It}$ is believed that thicker lesions can represent more advanced tumors with more intrinsic biological aggressiveness than those with radial growth only. ${ }^{21,22}$

According to Brauer et al.,thick melanomas increase the risk of early metastasis (between six months to three years of the initial tumor), compared to late metastases, that occur after eight years of the primary tumor. ${ }^{23}$ An increased risk of local or in-transit metastasis was seen with increased melanoma thickness in the study by Stucky et al. ${ }^{24}$ According to Faries et al., there was an increased risk of occult lymph node recurrence with thicker Breslow in patients with thin melanomas $(<1 \mathrm{~mm}) .{ }^{25}$ The case-control study conducted by Sartore et al.detected an increased risk of sentinel lymph node micrometastasis with the increased thickness of the primary tumor. ${ }^{26}$

The presence of ulceration was also considered an independent risk factor for the development of melanoma metastasis in this study. Many authors confirmed the importance of ulceration in the prognosis of melanoma and the reduction in disease-free survival and survival of patients..$^{27-29}$ According to Balch et al.,the presence of 
ulceration in patients with localized melanoma reduces survival in 5 years from $80 \%$ to $55 \% .^{30}$ The authors also observed that lesions with histological ulceration are associated to nodular and thicker tumors. Eigentler et al. showed the reduction in the 10-year survival in patients with T2 and T3 tumors (stage I) when ulceration was present. However, this variable did not influence $\mathrm{T} 1(\leq 1 \mathrm{~mm})$ and $\mathrm{T} 4(>4 \mathrm{~mm})$ tumors. ${ }^{31}$ Staging based on Breslow thickness and ulceration was the variable that most influenced 10-year survival in patients with localized melanoma in the study by Francken et al. ${ }^{32}$

According to the univariate analysis, the presence of mitoses in the histopathology was a statistically significant variable for the occurrence of metastasis in patients $(\mathrm{p}<0.0001)$. However, it was not possible to analyze it with the Cox method, because there was no metastasis in patients without detectable mitosis within the tumor. This invalidated the statistical method and the variable was excluded from the multivariate analysis. We can assume that, due to the low $\mathrm{p}$ value in the univariate analysis, the presence of mitosis is important for the prediction of metastasis in the study population.

According to Murali et al.,the presence of mitosis correlated with the reduction in the time for disease recurrence. ${ }^{33}$ The mitotic index was also significantly correlated to tumor thickness (Breslow thickness) and to the presence of ulceration, but was not independently significant in the overall survival of patients. Nagore et $a l .^{34}$ also detected a higher risk of metastasis in those tumors with mitosis, as well as Karjalainen et al. ${ }^{35}$ According to Gimotty et al., who studied 396 patients with thin melanoma, the patients diagnosed with metastasis within their tumors had a higher risk of recurrence in 10 years than those with a mitotic index of zero $(\mathrm{HR}=6.7){ }^{36}$ Svobodová et al. demonstrated that the presence of mitosis in the histopathology was associated to the reduction in disease-free survival $(R R=1.911) .{ }^{27}$ It is postulated that the mitotic index is related to a worse melanoma prognosis because it reflects a superior proliferative index, what would facilitate the occurrence of more aggressive cellular clones with a higher potential to create metastases. ${ }^{34,37}$

The results of this study show that age was not an independent variable to predict the risk for metastasis $(p>0.05)$. Even though the authors have not shown the influence of age in the recurrence of melanoma, what can actually have happened with the population in this study, another factor could explain the lack of association with age in the study sample: the lack of distinction between locoregional and distant metastases, grouped in a single outcome. ${ }^{38,39}$ Some authors postulate that the occurrence of lymph node metastasis is more common in younger individuals, and in contrast distant dissemination of the disease is lower and survival is higher in this group of patients..$^{28,40,41}$ Kretschmer et al. showed that patients younger than 40 years had a higher risk of sentinel lymph node metastasis. ${ }^{42}$ However, this age group had a lower risk of local and distant disease, besides a longer specific survival. Thus, the highest rates of lymph node metastasis that occur in younger patients could have been similar to the higher rates of distant metastasis in older patients in this study, affecting the final result.

In this study, family history of melanoma did not alter the disease-free survival $(\mathrm{p}=0.985)$. Similarly, Hornbuckle et al. did not show differences in recurrences, in the pattern of metastasis distribution and survival among patients with and without family histo- ry of melanoma either. ${ }^{43}$ Of note, the sample of patients with metastasis and family history of melanoma of this cohort was restricted: only 11 of the 135 patients with metastasis had family members with the disease. This limits the interpretation of the results regarding this variable. Considering the studies published to date, we cannot affirm that a positive family history of melanoma is a risk factor for disease progression.

This study did not show differences in the spreading of the disease among patients with axial tumors (head, neck and trunk) compared to those with tumors on the extremities (upper and lower limbs). Other authors did not find association between the site of the primary melanoma and disease progression either. ${ }^{44}$ According to Faries et al., the occurrence of lymph node metastasis was not associated to the site of the primary tumor. ${ }^{25}$ Patients with localized melanoma on the head and neck did not show a reduced survival when compared to those with tumors on other sites, as reported by Hoersh et al. The appearance of metastases was not influenced by the site of the primary tumor in the study by Kelly et al. M-raz Gernhard et al. did not find an association between the site of melanoma and the occurrence of lymph node micrometastasis. In patients with thick melanoma, there was no difference in the reduction of disease-free survival between those with axial tumors and those with tumors on the extremities, according to Kim et al. ${ }^{45-48}$

\section{Other considerations}

It is worth highlighting that $266(34.1 \%)$ patients were excluded from the final statistical analysis for not fulfilling the established inclusion criteria. Around half of these (137 individuals) had non-invasive primary cutaneous melanoma, evidencing that only $17.6 \%$ of the patients in the study were diagnosed in the early stages of the disease $(28.3 \%$ of the 212 patients admitted in the service of Dermatology and $13.6 \%$ of the 568 patients in the service of surgical oncology. The result contradicts other studies in the literature, that point to a diagnosis of in-situ melanoma in 25 to $30 \%$ of patients. ${ }^{4,49}$ This result can be explained by the occurrence of a selection bias due to the inclusion of a large number of patients seen at the service of surgical oncology, that are referred in more advanced stages of melanoma for the surgical treatment of locally advance or metastatic disease. Analyzing only the patients seen by dermatologists in the reference service of dermatology at the university hospital, the early stage diagnosis is similar to the results found in the literature (28.3\%).

The admission of patients in the service of surgical oncology in this study could also explain the increased number of cases diagnosed with regional or distant metastases. Of the 514 patients included in the final analysis, 135 (26.3\%) had metastatic disease. Literature data indicate that $10 \%$ of patients with invasive primary cutaneous melanoma progress with metastasis. ${ }^{1,4,49}$

Another observation to be considered is the reduction in the total number of patients submitted to the multivariate analysis with the Cox method. Since the study covered a period of 17 years and only recently factors such as ulceration and mitotic index were included in the AJCC staging of the disease, only 244 patients (47.5\%) of the total of 514 had data on the six prognostic factors for the final statistical model, with statistically significant results with the univariate analysis..$^{1,50}$ 
Another limitation of this study was not performing sentinel lymph node biopsy for all patients with melanomas with thickness between 1 and $4 \mathrm{~mm}$, what could have caused a reduction in the number of cases diagnosed with regional metastasis. This is due to the participation of patients from the public system that still lacks resources to perform the test in all indicated cases.

The anatomopathological diagnosis of melanoma was performed by only one experienced dermatopathologist in the service of dermatology. The diagnosis of those seen at the service of surgical oncology was performed in private laboratories and reviewed by a pathologist with experience in melanocytic lesions. Even though the anatomopathological examination performed by distinct examiners can affect the description of the histopathologic features of the tu- mor, we believe that this has not influenced the final results in the study, because only two experienced pathologists were responsible for the diagnosis of the cases.

It is important to highlight that the present study grouped the four types of metastasis (satellite, in-transit, lymph node and distant) in a single outcome. This can lead to dissonant results with studies previously published, where the metastases are studied separately according to the affected site.

\section{CONCLUSION}

Male gender, nodular clinicopathological type, Breslow thickness $>4 \mathrm{~mm}$ and the presence of ulceration were considered risk factors for the occurrence of metastasis in patients with primary cutaneous melanoma in this study. $\square$

\section{REFERENCES}

1. Balch CM, Gershenwald JE, Soong SJ, Thompson JF, Atkins MB, Byrd DR, et al. Final version of 2009 AJCC melanoma staging and classification. J Clin Oncol. 2009;27:6199-206.

2. Inca.gov.br [Internet]. Instituto Nacional do Câncer. Tipos de Câncer: Pele Melanoma. Rio de Janeiro: INCA; 2012. [acesso 21 jun 2012]. Disponível em: http://www2.inca.gov.br/wps/wcm/connect/inca/portal/home

3. Marsden JR, Newton-Bishop JA, Burrows L, Cook M, Corrie PG, Cox NH, et al. Revised UK guidelines for the management of cutaneous melanoma 2010. J Plast Reconstr Aesthet Surg. 2010;63:1401-19.

4. Pollack LA, Li J, Berkowitz Z, Weir HK, Wu XC, Ajani UA, et al. Melanoma survival in the United States, 1992 to 2005. J Am Acad Dermatol. 2011;65:S78-86.

5. Palmer SR, Erickson LA, Ichetovkin I, Knauer DJ, Markovic SN. Circulating serologic and molecular biomarkers in malignant melanoma. Mayo Clin Proc. 2011;86:981-90

6. Karakousis CP, Driscoll DL. Prognostic parameters in localised melanoma: gender versus anatomical location. Eur J Cancer. 1995;31A:320-4

7. Lindholm C, Andersson R, Dufmats M, Hansson J, Ingvar C, Möller T, et al. Invasive cutaneous malignant melanoma in Sweden, 1990-1999. A prospective, population-based study of survival and prognostic factors. Cancer. 2004;101:2067-78

8. de Vries E, Nijsten TE, Visser 0, Bastiaannet E, van Hattem S, Janssen-Heijnen $M L$, et al. Superior survival of females among 10,538 Dutch melanoma patients is independent of Breslow thickness, histologic type and tumor site. Ann Oncol. 2008;19:583-9.

9. Mervic L. Time course and pattern of metastasis of cutaneous melanoma differ between men and women. PLoS One. 2012;7:e32955.

10. Scoggins CR, Ross MI, Reintgen DS, Noyes RD, Goydos JS, Beitsch PD, et al. Gender-related differences in outcome for melanoma patients. Ann Surg. 2006;243:693-8

11. Miller JG, Gee J, Price A, Garbe C, Wagner M, Mac Neil S. Investigation of oestrogen receptors, sex steroids and soluble adhesion molecules in the progression of malignant melanoma. Melanoma Res. 1997;7:197-208.

12. Lens M, Rosdahl I, Newton-Bishop J. Cutaneous melanoma during pregnancy: is the controversy over? J Clin Oncol. 2009;27:e11-2.

13. Joosse A, De Vries E, van Eijck CH, Eggermont AM, Nijsten T, Coebergh JW. Reactive oxygen species and melanoma: an explanation for gender differences in survival? Pigment Cell Melanoma Res. 2010;23:352-64.
14. Kunte C, Geimer T, Baumert J, Konz B, Volkenandt M, Flaig M, et al. Prognostic factors associated with sentinel lymph node positivity and effect of sentinel status on survival: an analysis of 1049 patients with cutaneous melanoma. Melanoma Res. 2010;20:330-7.

15. Clark WH Jr, From L, Bernardino EA, Mihm MC. The histogenesis and biologic behavior of primary human malignant melanomas of the skin. Cancer Res. 1969;29:705-27.

16. Chang JW, Yeh KY, Wang $\mathrm{CH}$, Yang TS, Chiang HF, Wei FC, et al. Malignant melanoma in Taiwan: a prognostic study of 181 cases. Melanoma Res 2004; $14: 537-41$

17. Day CL Jr, Lew RA, Mihm MC Jr, Sober AJ, Harris MN, Kopf AW, et al. A multivariate analysis of prognostic factors for melanoma patients with lesions greater than or equal to $3.65 \mathrm{~mm}$ in thickness. The importance of revealing alternative Cox models. Ann Surg. 1982;195:44-9.

18. Viros A, Fridlyand J, Bauer J, Lasithiotakis K, Garbe C, Pinkel D, et al. Improving melanoma classification by integrating genetic and morphologic features. PLoS Med. 2008;5:e120.

19. Garbe C, Büttner P, Bertz J, Burg G, d'Hoedt B, Drepper H, et al. Primary cutaneous melanoma. Identification of prognostic groups and estimation of individual prognosis for 5093 patients. Cancer. 1995;75:2484-91.

20. Breslow A. Thickness, cross-sectional areas and depth of invasion in the prognosis of cutaneous melanoma. Ann Surg. 1970;172:902-8.

21. Balch CM, Murad TM, Soong SJ, Ingalls AL, Halpern NB, Maddox WA. A multifactorial analysis of melanoma: prognostic histopathological features comparing Clark's and Breslow's staging methods. Ann Surg. 1978;188:732-42.

22. Clark WH Jr, Ainsworth AM, Bernardino EA, Yang CH, Minm CM Jr, Reed RJ. The developmental biology of primary human malignant melanomas. Semin Oncol. 1975;2:83-103

23. Brauer JA, Wriston CC, Troxel AB, Elenitsas R, Shin DB, Guerry D, et al. Characteristics associated with early and late melanoma metastases. Cancer. 2010;116:415-23

24. Stucky CC, Gray RJ, Dueck AC, Wasif N, Laman SD, Sekulic A, et al. Risk factors associated with local and in-transit recurrence of cutaneous melanoma. Am J Surg. 2010;200:770-4.

25. Faries MB, Wanek LA, Elashoff D, Wright BE, Morton DL. Predictors of occult nodal metastasis in patients with thin melanoma. Arch Surg. 2010;145:137-42.

26. Sartore L, Papanikolaou GE, Biancari F, Mazzoleni F. Prognostic factors of cutaneous melanoma in relation to metastasis at the sentinel lymph node: a case- 
controlled study. Int J Surg. 2008;6:205-9.

27. Svobodová S, Browning J, MacGregor D, Pollara G, Scolyer RA, Murali R, et al. Cancer-testis antigen expression in primary cutaneous melanoma has independent prognostic value comparable to that of Breslow thickness, ulceration and mitotic rate. Eur J Cancer. 2011:47:460-9

28. Rutkowski P, Nowecki Zl, Zdzienicki M, Michej W, Symonides M, Rosinska M, et al. Cutaneous melanoma with nodal metastases in elderly people. Int J Dermatol. 2010;49:907-13

29. Göppner D, Ulrich J, Pokrywka A, Peters B, Gollnick H, Leverkus M. Sentinel lymph node biopsy status is a key parameter to stratify the prognostic heterogeneity of malignant melanoma in high-risk tumors >4.0 mm. Dermatology. 2011;222:59-66.

30. Balch CM, Wilkerson JA, Murad TM, Soong SJ, Ingalls AL, Maddox WA The prognostic significance of ulceration of cutaneous melanoma. Cancer. 1980;45:3012-7.

31. Eigentler TK, Buettner PG, Leiter U, Garbe C; Central Malignant Melanoma Registry of the German Dermatological Society. Impact of ulceration in stages I to III cutaneous melanoma as staged by the American Joint Committee on Cancer Staging System: an analysis of the German Central Malignant Melanoma Registry. J Clin Oncol. 2004;22:4376-83

32. Francken AB, Shaw HM, Thompson JF, Soong SJ, Accortt NA, Azzola MF, et al. The prognostic importance of tumor mitotic rate confirmed in 1317 patients with primary cutaneous melanoma and long follow-up. Ann Surg Oncol. 2004;11:426-33.

33. Murali R, Moncrieff MD, Hong J, Cooper CL, Shingde MV, Samuel DG, et al. The prognostic value of tumor mitotic rate and other clinicopathologic factors in patients with locoregional recurrences of melanoma. Ann Surg Oncol. 2010;17:2992-9.

34. Nagore E, Oliver V, Botella-Estrada R, Moreno-Picot S, Insa A, Fortea JM. Prognostic factors in localized invasive cutaneous melanoma: high value of mitotic rate, vascular invasion and microscopic satellitosis. Melanoma Res. 2005;15:169-77.

35. Karjalainen JM, Eskelinen MJ, Nordling S, Lipponen PK, Alhava EM, Kosma VM Mitotic rate and S-phase fraction as prognostic factors in stage I cutaneous malignant melanoma. Br J Cancer. 1998;77:1917-25

36. Gimotty PA, Van Belle P, Elder DE, Murry T, Montone KT, Xu X, et al. Biologic and prognostic significance of dermal Ki67 expression, mitoses, and tumorigenicity in thin invasive cutaneous melanoma. J Clin Oncol. 2005;23:8048-56.

37. Ostmeier H, Fuchs B, Otto F, Mawick R, Lippold A, Krieg V, et al. Can immunohistochemical markers and mitotic rate improve prognostic precision in patients with primary melanoma? Cancer. 1999;85:2391-9.

38. Chang CK, Jacobs IA, Vizgirda VM, Salti Gl. Melanoma in the elderly patient. Arch Surg. 2003;138:1135-8.

39. Kruiff S, Bastiaannet E, Suurmeijer AJ, Hoekstra HJ. Detection of melanoma nodal metastases; differences in detection between elderly and younger patients do not affect survival. Ann Surg Oncol. 2010;17:3008-14.

40. Chao C, Martin RC 2nd, Ross Ml, Reintgen DS, Edwards MJ, Noyes RD, et al. Correlation between prognostic factors and increasing age in melanoma. Ann Surg Oncol. 2004;11:259-64.

41. Chagpar RB, Ross MI, Reintgen DS, Edwards MJ, Scoggins CR, Martin RC 2nd et al. Factors associated with improved survival among young adult melanoma patients despite a greater incidence of sentinel lymph node metastasis. J Surg Res. 2007;143:164-8.

42. Kretschmer L, Starz H, Thoms KM, Satzger I, Völker B, Jung K, et al. Age as a key factor influencing metastasizing patterns and disease-specific survival after sentinel lymph node biopsy for cutaneous melanoma. Int J Cancer. 2011:129:1435-42.

43. Hornbuckle J, Culjak G, Jarvis E, Gebski V, Coates A, Mann G, et al. Patterns of metastases in familial and non-familial melanoma. Melanoma Res. 2003:13:105-9.
44. Corona R, Sciò M, Mele A, Ferranti G, Mostaccioli S, Macchini V, et al. Survival and prognostic factors in patients with localised cutaneous melanoma observed between 1980 and 1991 at the Istituto Dermopatico dell'Immacolata in Rome, Italy. Eur J Cancer. 1994;30A:333-8.

45. Hoersch B, Leiter U, Garbe C. Is head and neck melanoma a distinct entity? A clinical registry-based comparative study in 5702 patients with melanoma. $\mathrm{Br} \mathrm{J}$ Dermatol. 2006:155:771-7.

46. Kelly JW, Blois MS, Sagebiel RW. Frequency and duration of patient follow-up after treatment of a primary malignant melanoma. J Am Acad Dermatol. 1985;13:756-60

47. Mraz-Gernhard S, Sagebiel RW, Kashani-Sabet M, Miller JR 3rd, Leong SP. Prediction of sentinel lymph node micrometastasis by histological features in primary cutaneous malignant melanoma. Arch Dermatol. 1998;134:983-7.

48. Kim SH, Garcia C, Rodriguez J, Coit DG.. Prognosis of thick cutaneous melanoma. J Am Coll Surg. 1999;188:241-7.

49. Dennis LK. Analysis of the melanoma epidemic, both apparent and real: data from the 1973 through 1994 surveillance, epidemiology, and end results program registry. Arch Dermatol. 1999;135:275-80.

50. Balch CM, Buzaid AC, Soong SJ, Atkins MB, Cascinelli N, Coit DG, et al. Fina version of the American Joint Committee on Cancer staging system for cutaneous melanoma. J Clin Oncol. 2001:19:3635-48.

How to cite this article: Cherobin ACFP, Wainstein AJA, Colosimo EA, Goulart EMA, Bittencourt FV. Prognostic factors for metastasis in cutaneous melanoma. An Bras Dermatol. 2018;93(1):19-26. 